\title{
CORRELAÇÃO ENTRE ESCHERICHIA COLI E VARIÁVEIS LIMNOLÓGICAS EM AMOSTRAS DE ÁGUA DA LAGOA DA PARANGABA
}

\author{
Sá, M. V. C. ${ }^{*}$, Barbosa, A. K. T. ${ }^{2} \&$ Gomes, R. B. ${ }^{3}$ \\ 1 - Departamento de Engenharia de Pesca, Centro de Ciências Agrárias, Universidade Federal do \\ Ceará. Campus Universitário do Pici, s/n, bloco 827. Fortaleza, Ceará. CEP: 60.356-000. \\ *Corresponding author: marcelo.sa@ufc.br \\ 2 - Departamento de Engenharia de Pesca, CCA, Universidade Federal do Ceará. E.mail: \\ kellytabosa@hotmail.com \\ 3 - Laboratório Integrado de Águas de Mananciais e Residuárias, Centro Federal de Educação \\ Tecnológica - CEFET, Fortaleza, Ceará. E.mail: bemvindo@cefetce.br
}

\begin{abstract}
Sá, M. V. C.; Barbosa, A. K. T. \& Gomes, R. B. 2010. Correlation between Escherichia coli and limnological variables in water samples of the Lagoa da Parangaba. Braz. J. Aquat. Sci. Technol. 14(2): 33-40. ISSN 18087035. The present work aimed at evaluating the possible relationship between the Escherichia coli counts and the concentrations of free $\mathrm{CO}_{2}$, dissolved oxygen, reactive phosphorus, total ammonia, nitrite and $\mathrm{pH}$ in water samples of the Lagoa da Parangaba (Fortaleza, Ceará). Eight campaigns were carried out every fifteen days to collect sub-superficial water samples in three sampling spots. Regression analyses were performed upon the variable with the greatest linear Pearson coefficients looking for the curve that best fitted to the observed data. The correlation between the water free $\mathrm{CO}_{2}$ and $E$. coli was best represented by the equation $y=17.74-1.16^{\star} 10^{-3} \mathrm{x}+6.76^{*} 10^{-8} \mathrm{x}^{2}\left(\mathrm{R}^{2}=0.75 ; \mathrm{P}=0.06\right)$, where $\mathrm{x}$ is the E. coli count (MPN $100 \mathrm{~mL}^{-1}$ ) and $\mathrm{y}$ is the water carbon dioxide concentration ( $\left.\mathrm{mg} \mathrm{L}^{-1}\right)$. It was concluded that the rich organic matter inflows of the Lagoa da Parangaba, mainly of fecal origin, have increased not only the sanitary risk to the population that use this water source, but also affected the life of the animal populations that live in it. It was also observed that the Lagoa da Parangaba's waters are highly contaminated by E. coli. Besides, they are acidic and suffer eventual episodes of hypoxia.
\end{abstract}

Keywords: Eutrophication. Fecal coliforms. Carbon dioxide.

\section{INTRODUÇÃO}

Um dos campos mais antigos da Limnologia, e um dos mais importantes nos tempos atuais, refere-se às pesquisas sobre o metabolismo dos ecossistemas aquáticos continentais. Essas pesquisas possibilitam o conhecimento da estrutura e do funcionamento desses ecossistemas, viabilizando o seu manejo e a maximização da sua produtividade. Os resultados obtidos nesses estudos constituem a ferramenta mais importante para várias técnicas de manejo, destacandose a aqüicultura de água doce (Esteves, 1998).

A Lagoa da Parangaba (LP), localizada na cidade de Fortaleza, Estado de Ceará, pertence à Bacia Hidrográfica do Maranguapinho. Nessa Bacia também estão presentes a Lagoa do Mondubim e o Açude Santo Anastácio, dentre outros corpos hídricos da Região Metropolitana de Fortaleza. A LP possui espelho d'água de 40,7 ha, volume de $1.190 .000 \mathrm{~m}^{3}$ e perímetro de $2.700 \mathrm{~m}$. Apresenta profundidade média e máxima de 2,77 e 4,92 m, respectivamente, e não possui comunicação com o mar. Possui $4.070 \mathrm{~m}^{2}$ de área potencial para aqüicultura, o que corresponde a $1 \%$ da área do espelho d'água. Apesar disso, ainda não há atividade aqüícola sendo desenvolvida na LP até o presente momento, verificando-se apenas a pesca esportiva, que é realizada de forma eventual e desorganizada, principalmente nos finais de semana.

Segundo a Secretaria Municipal de Meio Ambiente e Controle Urbano - SEMAN, da Prefeitura Municipal de Fortaleza, as águas da LP são impróprias para banho. De acordo com o boletim da SEMAN, datado de 10/9/2008, a concentração média de coliformes termotolerantes na LP foi igual a $7501 \mathrm{NMP} 100 \mathrm{~mL}^{-1}$, tendo como limite máximo para balneabilidade $500 \mathrm{NMP}$ $100 \mathrm{~mL}^{-1}$. A concentração média de Escherichia coli foi de 6.409 NMP $100 \mathrm{~mL}^{-1}$, contra o padrão de aceitação de 400 NMP $100 \mathrm{~mL}^{-1}$.

Tendo como referência a Resolução № 357-05 do Conselho Nacional do Meio Ambiente - CONAMA e o referido relatório de balneabilidade expedido pela SEMAN, citado acima, as águas da LP se enquadram na Classe 4, sendo destinadas apenas à harmonia paisagística. Portanto, o atual estado físico-químico das águas torna a LP inadequada para aqüicultura.

Para que se possa recuperar a LP e torná-la novamente apta a receber projetos de aqüicultura, faz-se imperativo a realização de estudos sistemáticos sobre 
sua limnologia. É necessário que o lago seja submetido primeiramente a intenso programa de pesquisas limnológicas básicas, visando um diagnóstico preciso, antes que se possa iniciar sua recuperação (Esteves, 1998).

Dentre os pontos de importância que carecem esforço de pesquisa, destaca-se a possível correlação entre as contagens de Escherichia colipresente na água e sua físico-química. Assim, o presente trabalho teve como objetivo avaliar a possível correlação existente entre as contagens de $E$. coli e as concentrações de $\mathrm{CO}_{2}$ livre, oxigênio dissolvido, fósforo reativo, amônia total e nitrito, em amostras de água da LP. Além desses, considerou-se ainda o pH da água.

\section{MATERIAL E MÉTODOS}

As campanhas foram realizadas na Lagoa da Parangaba (LP) e as amostras de água foram analisadas no Laboratório de Limnologia - LABLIM/DEP/UFC, do Departamento de Engenharia de Pesca, da Universidade Federal do Ceará, e no Laboratório Integrado de Águas de Mananciais e Residuárias - LIMAR/ CEFETCE, do Centro Federal de Educação Tecnológica do Ceará. Foram realizadas oito campanhas, com periodicidade quinzenal, nas quais se coletou amostras da água sub-superficial (20 - $30 \mathrm{~cm}$ de profundidade) da LP, em três pontos de amostragem (Tabela 1). As estações de amostragem foram definidas como entrada d'água (tributário principal), centro e sangradouro. As estações "entrada" e "sangradouro" eram pontos de margem. A estação "centro" era ponto de meio.

As campanhas de coleta foram realizadas juntamente com o pessoal do LIAMAR/CEFETCE, por ocasião do trabalho de avaliação da balneabilidade da LP, dentro do Programa "Lagoas de Fortaleza" da Prefeitura Municipal de Fortaleza. Portanto, nos momentos e pontos exatos em que ocorriam as coletas de amostras de água para análise microbiológica (E.coli), no LIAMAR/CEFETCE, ocorriam as coletas de amostras

Tabela 1 - Coordenadas geográficas dos pontos amostrados na Lagoa da Parangaba (Fortaleza, Ceará)

\begin{tabular}{lcc}
\hline \hline Estação & Latitude & Longitude \\
\hline Entrada & $3^{\circ} 46,337^{\prime} \mathrm{S}$ & $38^{\circ} 31,882^{\prime} \mathrm{W}$ \\
Centro & $3^{\circ} 46,237^{\prime} \mathrm{S}$ & $38^{\circ} 31,820^{\prime} \mathrm{W}$ \\
Sangradouro & $3^{\circ} 46,163^{\prime} \mathrm{S}$ & $38^{\circ} 31,731^{\prime} \mathrm{W}$ \\
\hline \hline
\end{tabular}

de água para análise físico-química, no LABLIM/DEP/ UFC.

O trabalho de coleta de amostras de água da LP foi realizado sempre aos sábados, entre nove e dez horas da manhã. Inicialmente, o barco do LIAMAR/ CEFETCE se dirigia ao primeiro ponto de coleta, localizado próximo à margem da LP, onde é realizada a chamada "Feira dos carros". Um pouco antes da chegada ao ponto de coleta, o motor do barco era desligado para diminuir a movimentação da água. Em seguida, o barco era ancorado para realização das coletas.

Como já referido, a água era coletada manualmente a uma profundidade de aproximadamente trinta centímetros da superfície (tomando como base o comprimento do braço, a linha da água deveria estar acima do cotovelo). Nesse exato momento, os alunos do LIMAR/CEFETCE realizavam a coleta de amostras de água para análise microbiológica.

As amostras de água eram envasadas em garrafas plásticas opacas (brancas), com capacidade de um litro, e imediatamente acondicionadas em caixa de isopor ou bolsa térmica. As garrafas de coleta eram cheias ao máximo e fechadas ainda dentro d'água para impedir a formação de bolhas no seu interior. Foram coletados dois litros de água (duas garrafas) para cada ponto amostrado.

Terminado o trabalho de coleta no primeiro ponto, o barco seguia para o segundo ponto de coleta, que fica localizado próximo ao meio geográfico da lagoa, e para o terceiro ponto, situado no sangradouro da LP. Os mesmos procedimentos realizados no primeiro ponto eram repetidos nos dois pontos seguintes.

Ao todo, a coleta durava em torno de vinte minutos. Após isso, as amostras eram levadas imediatamente ao LABLIM/DEP/UFC, onde as análises eram realizadas em caráter de urgência. O tempo decorrido entre a coleta da água no primeiro ponto na LP e o início da sua análise no laboratório era de, no máximo, uma hora.

As seguintes variáveis físico-químicas foram observadas nas amostras de água, em duplicata: oxigênio dissolvido, salinidade, alcalinidade total, dureza cálcica, $\mathrm{pH}, \mathrm{CO}_{2}$ livre, fósforo reativo, amônia total, nitrito, ferro e condutividade elétrica. As análises físicoquímicas foram realizadas de acordo com as metodologias utilizadas no LABLIM/DEP/UFC, as quais estão baseadas em APHA (1999). As concentrações de Escherichia coli nas amostras de água foram determinadas de acordo com o método 9223-B da APHA (1999), com a utilização de substrato cromogênico ONPG-MUG.

Tendo em vista as sugestões apontadas pela literatura especializada (Kulkoyluoglu et al., 2007), apenas os resultados de oxigênio dissolvido, $\mathrm{pH}, \mathrm{CO}_{2}$ livre, fósforo reativo, amônia total e nitrito foram 
Tabela 2 - Características físico-químicas da água de entrada, meio e sangradouro da Lagoa da Parangaba (Fortaleza, Ceará) em amostras de água sub-superficial coletadas no período de 5/4 a 20/9/2008 (média \pm d.p.). O $\mathrm{D}$ : oxigênio dissolvido na água (mg $\mathrm{L}^{-1}$ ), $\mathrm{S}$ : salinidade, $\mathrm{CE}$ : condutividade elétrica $\left(\mathrm{mS} \mathrm{cm}^{-1}\right)$, AlcT: alcalinidade total ( $\left.\mathrm{mg} \mathrm{L}^{-1} \mathrm{CaCO}_{3}\right)$, DurCa: dureza cálcica $\left(\mathrm{mg} \mathrm{L}^{-1} \mathrm{CaCO}_{3}\right), \mathrm{CO}_{2} \mathrm{~L}: \mathrm{gás}^{-1}$ carbônico livre $\left(\mathrm{mg} \mathrm{L}^{-1}\right)$, Pr: fósforo reativo $\left(\mathrm{mg} \mathrm{L}^{-1}\right), \mathrm{NH}_{3} \mathrm{~T}$ : amônia total ( $\left.\mathrm{mg} \mathrm{L}^{-1}\right), \mathrm{NH}_{3}$ Tox: amônia tóxica (mg L-1), $\left.\mathrm{NO}_{2}: \mathrm{nitrito}^{3} \mathrm{mg} \mathrm{L}^{-1}\right), \mathrm{FeT}^{-}$: ferro total $\left(\mathrm{mg} \mathrm{L}^{-1}\right)$; CV: Coeficiente de variação (\%).

\begin{tabular}{cccccccc}
\hline \hline \multirow{2}{*}{ Variável } & \multicolumn{3}{c}{ Ponto de coleta } & Média \pm d.p. & CV (\%) & Min & Max \\
& Entrada & Meio & Sangradouro & & & & \\
\hline $\mathrm{O}_{2} \mathrm{D}$ & $4,7 \pm 0,65$ & $4,8 \pm 0,63$ & $5,6 \pm 1,03$ & $5,04 \pm 0,51$ & 10,21 & 3,8 & 6,7 \\
$\mathrm{~S}$ & $0,30 \pm 0,03$ & $0,31 \pm 0,04$ & $0,30 \pm 0,03$ & $0,30 \pm 0,004$ & 1,44 & 0,25 & 0,36 \\
$\mathrm{CE}$ & $614 \pm 78,5$ & $611 \pm 80,0$ & $611 \pm 79,5$ & $612,5 \pm 1,32$ & 0,22 & 552 & 784 \\
$\mathrm{AlcT}$ & $50,9 \pm 31,2$ & $50,6 \pm 30,8$ & $50,3 \pm 31,8$ & $50,6 \pm 0,29$ & 0,57 & 1,5 & 75,5 \\
$\mathrm{DurCa}$ & $59,3 \pm 6,2$ & $59,3 \pm 5,2$ & $61,0 \pm 4,2$ & $59,8 \pm 0,09$ & 1,66 & 51,1 & 68,1 \\
$\mathrm{pH}$ & $7,43 \pm 0,88$ & $7,44 \pm 0,71$ & $7,58 \pm 0,89$ & $7,48 \pm 0,08$ & 1,1 & 5,7 & 8,7 \\
$\mathrm{CO}_{2} \mathrm{~L}$ & $16,0 \pm 6,3$ & $17,8 \pm 5,1$ & $14,3 \pm 6,6$ & $16,0 \pm 1,75$ & 10,9 & 5,0 & 28,5 \\
$\mathrm{Pr}$ & $0,02 \pm 0,03$ & $0,02 \pm 0,02$ & $0,02 \pm 0,03$ & $0,021 \pm 0,003$ & 12,63 & 0,0 & 0,09 \\
$\mathrm{NH}_{3} \mathrm{~T}$ & $0,27 \pm 0,13$ & $0,29 \pm 0,17$ & $0,28 \pm 0,12$ & $0,28 \pm 0,008$ & 2,75 & 0,0 & 0,53 \\
$\mathrm{NH}_{3} \mathrm{Tox}$ & $0,016 \pm 0,02$ & $0,014 \pm 0,01$ & $0,018 \pm 0,02$ & $0,016 \pm 0,002$ & 12,9 & 0,0 & 0,06 \\
$\mathrm{NO}_{2}-$ & $0,77 \pm 0,55$ & $1,00 \pm 0,64$ & $0,92 \pm 0,55$ & $0,90 \pm 0,11$ & 12,8 & 0,13 & 1,70 \\
$\mathrm{FeT}^{-}$ & $0,14 \pm 0,19$ & $0,14 \pm 0,13$ & $0,14 \pm 0,12$ & $0,14 \pm 0,001$ & 0,58 & 0,0 & 0,56 \\
\hline \hline
\end{tabular}

correlacionados com as concentrações de E. coli, cujos valores são disponibilizados semanalmente pelo LIAMAR/CEFETCE na página da SEMAN na internet (http://www.seman.fortaleza.ce.gov.br)

Para a variável que apresentou o maior coeficiente de correlação linear em módulo, realizou-se a análise de regressão dos dados para determinação da curva que melhor se ajustava aos pontos observados. Em seguida, a partir do gráfico obtido e do resultado da análise de variância da regressão, discutiu-se as possíveis explicações ambientais e biológicas para os fenômenos observados, bem como as principais implicações dessas relações na manutenção do equilíbrio (ou desequilíbrio) ecológico da LP. Todas as análises estatísticas e matemáticas foram realizadas com o auxílio dos softwares Microsoft Office Excel 2007 e SigmaStat 2.0 (Jandel Statistics).

\section{RESULTADOS E DISCUSSÃO}

\section{Características físico-químicas da água}

A Tabela 2 apresenta os resultados das análises físico-químicas das amostras de água sub-superficial coletadas na entrada, meio e sangradouro da LP, no período de 5 de abril a 20 de setembro de 2008. Os valores de referência apresentados a seguir foram retirados de Boyd \& Tucker (1998).

A concentração média de oxigênio dissolvido na água sub-superficial da LP ficou em 5,04 $\pm 0,51 \mathrm{mg} \mathrm{L}^{-1}$, com extremos de 3,8 e 6,7 $\mathrm{mg} \mathrm{L}^{-1}$. A água sub-superficial do sangradouro apresentou concentração de oxigênio dissolvido $\left(5,6 \mathrm{mg} \mathrm{L}^{-1}\right)$ maior que o observado para a entrada $\left(4,7 \mathrm{mg} \mathrm{L}^{-1}\right)$ e meio $\left(4,8 \mathrm{mg} \mathrm{L}^{-1}\right)$.

A concentração média de oxigênio dissolvido na água sub-superficial da LP (5,04 $\left.\mathrm{mg} \mathrm{L}^{-1}\right)$, apesar de estar pouco acima do limite mínimo de adequação para aqüicultura, que é de 5,0 mg L-1 (Boyd \& Tucker, 1998), permite afirmar que a LP sofre eventuais episódios de hipóxia. Essa afirmação é referendada ao se observar o menor valor de oxigênio dissolvido na água observado durante as coletas $\left(3,8 \mathrm{mg} \mathrm{L}^{-1}\right)$. Quando a concentração de oxigênio dissolvido na água cai abaixo de 4,0 $\mathrm{mg} \mathrm{L}^{-1}$, os processos decompositores anaeróbios começam a prevalecer sobre os processos aeróbios (Esteves, 1998, p.150). Além disso, é preciso considerar que a água sub-superficial, coletada a $20-30 \mathrm{~cm}$ de profundidade, apresenta, geralmente, concentração de oxigênio dissolvido bem maior que a água de fundo. Portanto, caso se tivesse coletado também amostras da água de fundo, valores ainda menores de oxigênio 
dissolvido na água seriam observados, talvez próximos a zero.

A salinidade média da água da LP foi de $0,3 \pm$ 0,004 , com variação de 0,25 - 0,36, no período amostrado. Não houve variação importante na salinidade da água entre os pontos de coleta. A condutividade elétrica (CE) da água sub-superficial da LP ficou em 612,5 $\pm 1,32 \mathrm{mS} \mathrm{cm}^{-1}$, com valor mínimo e máximo de $522 \mathrm{e}$ $784 \mathrm{mS} \mathrm{cm}^{-1}$, respectivamente. Assim como ocorrido para salinidade, também não se verificou diferenças expressivas entre a CE dos pontos de coleta.

A salinidade média da água da $\operatorname{LP}(0,3)$ classifica-a como possuindo água doce, que é aquele ecossistema que apresenta menos de 0,5 de sais dissolvidos (CONAMA, 2005). A CE da água está bem acima do limite de referência para eutrofização de ecossistemas lacustres, que é de $100 \mathrm{mS} \mathrm{cm}^{-1}$ (Wetzel, 2001). A CE expressa a capacidade da água de propagar corrente elétrica e é função da concentração de sais dissolvidos na água. Em ambientes eutrofizados, nos quais há grande concentração de matéria orgânica particulada e dissolvida em decomposição, há uma elevação na CE devido ao processo de mineralização desses compostos. Portanto, tomando por base o valor médio de CE obtido no presente trabalho $\left(612 \mathrm{~S} \mathrm{~cm}^{-1}\right)$, pode-se classificar como eutrófico o nível de trofia da LP.

$\mathrm{O} \mathrm{pH}$ médio da água da LP foi de $7,48 \pm 0,08$, com variação entre 5,7 e 8,7. Os três pontos de coleta estudados, isto é, entrada, meio e sangradouro, apresentaram valores similares de $\mathrm{pH}$. No período de amostragem do presente trabalho, a alcalinidade total da água da LP foi, em média, igual a 50,6 $\pm 0,29 \mathrm{mg} L$ ${ }^{1}$ eq. $\mathrm{CaCO}_{3}$, com extremos de 1,5 e $75,5 \mathrm{mg} \mathrm{L}^{-1}$. Não se observou diferenças apreciáveis entre os três pontos de coleta para alcalinidade da água. A dureza cálcica média da água, em mg L-1 eq. $\mathrm{CaCO}_{3}$, foi igual a 59,8 \pm 0,99 , variando de 51,1 a $68,1 \mathrm{mg} \mathrm{L}^{-1}$. Assim como para alcalinidade, também não houve diferenciação entre os pontos de coleta para dureza cálcica da água.

Apesar do valor médio de $\mathrm{pH}$ estar dentro da faixa de adequação para o bom desenvolvimento de organismos aquáticos, que vai de 6,5 a 9,0, houve a ocorrência de baixos valores que fugiram dessa faixa. Há, portanto, na LP, em determinados períodos do ano, processos que levam a acidificação da sua água, com a verificação de valores de pH abaixo de 6,0. Nessa situação, o estresse ácido a que são submetidos os organismos aquáticos alteram a permeabilidade de suas membranas biológicas, provocando distúrbios osmorregulatórios, que podem levá-los a morte. Esses episódios de águas ácidas devem estar associados, provavelmente, a ocorrência de chuvas e/ou as eventuais descargas de esgotos domésticos na LP. Essa sugestão é apoiada pelos resultados de alcalinidade total, discutidos a seguir.

Dentre as variáveis físico-químicas da água afetadas pelo processo de acidificação, uma das primeiras é a alcalinidade da água. A alcalinidade total da água se refere à riqueza de íons bicarbonato e carbonato presentes na mesma (Dodds, 2002). No período de realização do presente trabalho, observou-se valores de alcalinidade total tão baixos quanto $1,5 \mathrm{mg} \mathrm{L}^{-1}$ eq. $\mathrm{CaCO}_{3}$, ou seja, quase ausência de alcalinidade na água. Esse fato, alcalinidade total igual a zero, ocorre quando o pH da água é igual ou menor a 4,5, limite inferior para vida aquática. Logo, durante as ocorrências das chuvas e/ou descargas de esgotos na LP, com o aumento na presença de íons $\mathrm{H}^{+}$no meio, houve queda contínua na alcalinidade da água, tornado o ambiente suscetível ao conseqüente processo de acidificação.

A dureza cálcica média da água da LP de quase $60 \mathrm{mg} \mathrm{L}^{-1}$ eq. $\mathrm{CaCO}_{3}$ permitem classificar sua água como moderadamente dura, apresentando concentrações de cálcio dissolvido que atendem as exigências dos organismos vivos para esse mineral.

A concentração média de $\mathrm{CO}_{2}$ livre na água subsuperficial da LP foi de $16,0 \pm 1,75 \mathrm{mg} \mathrm{L}^{-1}$, tendo-se observado valores extremos de 5,0 e $28,5 \mathrm{mg} \mathrm{L}^{-1}$. O sangradouro, que além de ter apresentando maior concentração de oxigênio dissolvido que a entrada e o meio, apresentou também menor concentração média de $\mathrm{CO}_{2}$ livre (14,3 $\left.\mathrm{mg} \mathrm{L}^{-1}\right)$, em relação aos outros dois pontos amostrados. A concentração média de fósforo reativo da água da LP, em mg L-1, foi de 0,021 $\pm 0,003$, com limites de mínimo e de máximo de 0,00 e 0,09 $\mathrm{mg} \mathrm{L}^{-1}$, respectivamente. O ponto de meio apresentou concentração de fósforo reativo abaixo da observada para os pontos de entrada e sangradouro.

A concentração média de $\mathrm{CO}_{2}$ livre na água da LP $\left(16,0 \mathrm{mg} \mathrm{L}^{-1}\right)$ está acima do limite máximo de adequação para o bom desenvolvimento de animais aquáticos, que é de $10 \mathrm{mg} \mathrm{L}^{-1}$. Nessa situação, os peixes não conseguem respirar normalmente, podendo vir a morrer por acidose respiratória (Danley et al., 2005) . A relação inversa entre a concentração de $\mathrm{O}_{2}$ dissolvido e $\mathrm{CO}_{2}$ livre no sangradouro pode ser explicada pelo fato da respiração ser, tecnicamente falando, o inverso da fotossíntese. Assim, enquanto as microalgas retiram $\mathrm{CO}_{2}$ da água e liberam $\mathrm{O}_{2}$, os organismos heterotróficos retiram $\mathrm{O}_{2}$ e liberam $\mathrm{CO}_{2}$. Logo, o sangradouro da LP apresentou-se como o ponto mais favorável para o crescimento dos peixes que ali vivem. Essa sugestão, contudo, não é sustentada pelo resultado de amônia tóxica, que se apresentou mais elevado no sangradouro. Novas coletas e observações se fazem necessárias para elucidar essa questão.

A discussão da concentração de fósforo reativo presente na água da LP se torna difícil porque as refe- 
rências encontradas na literatura são geralmente para fósforo total e não para fósforo reativo. Fósforo reativo é o resultado da determinação fotocolorimétrica da concentração de fosfato de uma amostra de água bruta e não digerida. Compreende o ortofosfato, que é a forma mais abundante, e um pouco do resultado da hidrólise espontânea de fósforo orgânico dissolvido e fósforo inorgânico particulado (APHA, 1999). Entretanto, podemos comparar o resultado de fósforo reativo obtido no presente trabalho $\left(21 \mathrm{\mu g} \mathrm{L}^{-1}\right)$ com os obtidos por Fantin-Cruz et al. (2008), na Lagoa das Pedras (Nossa Senhora do Livramento, Mato Grosso, Brasil). Esses autores observaram concentrações de ortofosfato na Lagoa das Pedras que variaram de $20 \mathrm{mg} \mathrm{L}^{-1}$, no período das chuvas, a $110 \mathrm{mg} \mathrm{L}^{-1}$, no período da estiagem. Como o presente trabalho também foi realizado no período chuvoso do ano em Fortaleza (Ceará), há grande semelhança entre os resultados de ortofosfato dos dois trabalhos. Logo, podemos inferir que caso o presente trabalho tivesse sido realizado no período seco do ano ( $2^{\circ}$ semestre), concentrações bem mais elevadas de ortofosfato teriam sido observadas por conta do efeito da estiagem em concentrar compostos dissolvidos na água.

As concentrações médias de amônia total e amônia tóxica na água sub-superficial da LP foram de $0,28 \pm 0,008$ e $0,016 \pm 0,002 \mathrm{mg} \mathrm{L}^{-1}$, respectivamente. As variações de amônia total no período de observações ficaram compreendidas entre 0,00035 e 0,53 mg $\mathrm{L}^{-1}$, não havendo diferenciação importante entre os pontos de coleta. Já as variações na concentração de amônia tóxica ficaram entre 0,0 e $0,06 \mathrm{mg} \mathrm{L}^{-1}$, com o ponto de meio apresentando o menor valor médio $(0,014)$ e o sangradouro o maior $\left(0,018 \mathrm{mg} \mathrm{L}^{-1}\right)$.

A concentração de amônia tóxica na água subsuperficial da LP $\left(0,016 \mathrm{mg} \mathrm{L}^{-1}\right)$ está abaixo do limite a partir do qual há estresse dos animais, que é de 0,05 $\mathrm{mg} \mathrm{L}^{-1}$. Contudo, o valor máximo observado no período de amostragens, isto é, 0,06 $\mathrm{mg} \mathrm{L}^{-1}$, apesar de subletal, já é capaz de causar alterações patológicas nos rins, baço e tireóide dos peixes, assim como provocar danificação no epitélio branquial dos mesmos (Arana, 2000).

A concentração média de nitrito da água da LP foi de $0,90 \pm 0,11 \mathrm{mg} \mathrm{L}^{-1}$, com variação entre $0,13 \mathrm{e}$ $1,70 \mathrm{mg} \mathrm{L}^{-1}$. A entrada da LP apresentou concentração de nitrito abaixo dos pontos de meio e sangradouro. $A$ concentração de ferro total, em mg L-1, foi, em média, igual a 0,14 0,001, com extremos de 0,00 e 0,56 mg L1 . Os três pontos de coleta apresentaram concentrações de ferro total muito similares entre si.

A concentração média de nitrito observada na água da LP $\left(0,9 \mathrm{mg} \mathrm{L}^{-1}\right)$ já se encontra acima do nível máximo de adequação para aqüicultura que é de 0,3 $\mathrm{mg} \mathrm{L}^{-1}$ (Boyd \& Tucker, 1998) O nitrito oxida o ferro da hemoglobina, tornando-a incapaz de transportar oxigênio. O pigmento respiratório muda de vermelho para marrom, fato esse que batizou essa patologia como a "doença do sangue marrom" (Golombieski et al., 2005). Entretanto, é importante destacar que o limite teórico de letalidade foi obtido a partir de estudos com espécies menos tolerantes ao nitrito, como os salmonídeos. Os peixes tropicais, em especial as tilápias, são bastante tolerantes a esse metabólito, podendo viver bem em águas com até 2,8 $\mathrm{mg} \mathrm{L}^{-1}$ de nitrito (Yanbo et al., 2006).

Apesar do valor médio de ferro total na água da LP $\left(0,14 \mathrm{mg} \mathrm{L}^{-1}\right)$ estar abaixo do limite para adequação para o crescimento de peixes, que é de $0,5 \mathrm{mg} \mathrm{L}^{-1}$, observaram-se valores que superaram essa marca, como, por exemplo, 0,56 $\mathrm{mg} \mathrm{L}^{-1}$. Quando em excesso, o ferro na água impede a correta utilização de outros micronutrientes essenciais a saúde animal, como zinco e cobre (Sá, 2003). Portanto, em certos períodos do ano há risco de toxicidade por ferro na LP. Esses períodos coincidem, provavelmente, com os momentos mais críticos de falta ou escassez de oxigênio dissolvido na água, uma vez que, nessas condições, há o desprendimento do ferro do sedimento para coluna d'água (Esteves, 1998).

\section{Coeficientes de correlação linear}

Das doze variáveis limnológicas monitoradas no presente trabalho (Tabela 2), selecionou-se seis para serem correlacionadas com as respectivas concentrações de E. coli. O critério de seleção adotado foi a possível aderência das variáveis limnológicas em questão com as alterações na carga de matéria fecal presente na LP, de acordo com a literatura especializada (Kulkoyluoglu et al., 2007).

A Tabela 3 apresenta os coeficientes de correlação linear de Pearson ( $r$ ) das relações entre as concentrações de $E$. coli e as seis variáveis limnológicas selecionadas. Em cada data, realizou-se o agrupamento dos dados dos diferentes pontos de amostragem (en-

Tabela 3 - Coeficientes de correlação linear de Pearson $(r)$ das relações entre as concentrações de Escherichia coli (NMP 100 $\mathrm{mL}^{-1}$ ) e variáveis limnológicas selecionadas de amostras de água da Lagoa da Parangaba (Fortaleza, Ceará)

\begin{tabular}{lcc}
\hline \hline \multicolumn{1}{c}{ Variável } & $r$ & Classificação \\
\hline $\mathrm{CO}_{2}$ livre & 0,62 & $1^{\circ}$ \\
$\mathrm{pH}$ & 0,48 & $2^{\circ}$ \\
Nitrito & 0,41 & $3^{\circ}$ \\
Amônia Total & 0,33 & $4^{\circ}$ \\
Fósforo reativo & 0,19 & $5^{\circ}$ \\
Oxigênio dissolvido & $-0,08$ & $6^{\circ}$ \\
\hline \hline
\end{tabular}




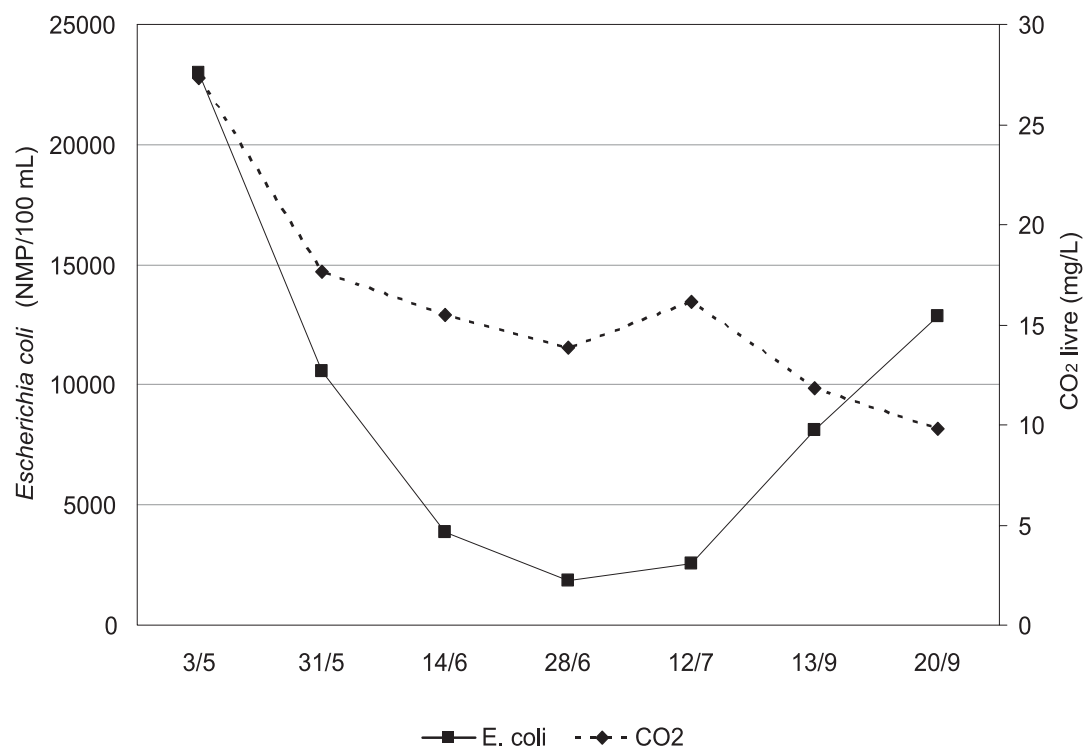

Figura 1 - Concentrações médias de Escherichia coli (NMP $\left.100 \mathrm{~mL}^{-1}\right)$ e $\mathrm{CO}_{2}$ livre $\left(\mathrm{mg} \mathrm{L}^{-1}\right)$ em amostras de água coletadas na entrada, meio e sangradouro da Lagoa da Parangaba (Fortaleza, Ceará), no período de $3 / 5$ a 20/9/2008.

trada, meio e sangradouro). Foram correlacionados os resultados de oxigênio dissolvido, $\mathrm{pH}, \mathrm{CO}_{2}$ livre, amônia total, nitrito e fósforo reativo com as concentrações de E. coli, em NMP $100 \mathrm{~mL}^{-1}$, divulgadas semanalmente pelo LIAMAR/CEFETCE. Em seguida, classificaramse as variáveis de acordo com o seu respectivo coeficiente de correlação, em ordem decrescente de importância. Dessa forma, a variável limnológica que apresentou o maior coeficiente de correlação, em módulo, foi a concentração de $\mathrm{CO}_{2}$ livre $(r=0,62)$. Essa variável foi posteriormente ajustada matematicamente aos resultados de concentração de $E$. coliatravés de análise de regressão polinomial.

\section{Relação entre $\mathrm{CO}_{2}$ livre e concentração de Escherichia coli}

A concentração média de $\mathrm{CO}_{2}$ livre na água subsuperficial da $L P$ variou de 9,8 a $27,3 \mathrm{mg} \mathrm{L}^{-1}$ no período de observações do presente trabalho (3/5 a 20/9/08), com valor médio de 16,0 $\pm 5,65 \mathrm{mg} \mathrm{L}^{-1}$ (Figura 1). $\mathrm{O}$ pico de $\mathrm{CO}_{2}$ livre foi observado por ocasião da primeira coleta realizada, em $3 / 5$. Já a menor concentração de $\mathrm{CO}_{2}$ livre ocorreu na última amostragem, em 20/9. Após a primeira amostragem, a concentração de $\mathrm{CO}_{2}$ livre na água da LP diminuiu progressivamente, excetuando-se em 12/7, quando teve um pequeno aumento.

Quando se comparam as variações nas concentrações médias de $\mathrm{CO}_{2}$ livre na água com as variações nas concentrações médias de E. coli, observa-se que há um relacionamento direto entre essas duas variáveis (Figura 1). Essa tendência, contudo, somente não foi observada nas duas últimas coletas realizadas, em 13 e 20/9, quando houve relacionamento inverso. De qualquer forma, assim como já indicado pelo coeficien- te de correlação de Pearson ( $r=0,62$; Tabela 3), há prevalência do relacionamento positivo sobre negativo, como verificado na maioria das campanhas de coleta realizadas $(3 / 5,31 / 5,14 / 6,28 / 6$ e 12/7).

A bactéria heterotrófica Gram-negativa Escherichia coli é anaeróbia facultativa e pertence à família das Enterobacteriaceae, que são bactérias colonizadoras do trato intestinal dos animais homeotermos. Dentro dessa família, encontram-se bactérias patogênicas por excelência, tais como Salmonella, Shigella e Yersinia; e bactérias que, excetuando-se quando em número muito elevado, convivem em equilíbrio com o organismo hospedeiro, tais como Enterobactere Klebsiella. A bactéria E. coli pertence a esse último grupo que, atualmente, é chamado de coliformes termotolerantes.

O trato intestinal dos animais homeotermos, bem como dos humanos, sejam saudáveis ou doentes, está geralmente colonizado por E. coli. Essa bactéria pode causar diarréia quando em número muito elevado no intestino. A concentração de E. coli em amostras de água é um dos principais indicadores biológicos de contaminação fecal utilizados pelo homem (Higgins \& Hohn, 2008).

As variações na concentração média de $E$. coli na LP se deveram, provavelmente, a ocorrência da descarga de esgotos domésticos na lagoa e/ou de chuvas. Com a entrada de esgotos domésticos na lagoa, há o aporte de significativa quantidade de matéria fecal no ecossistema. Por conseqüência, observa-se, nessas situações, aumento na concentração de bactérias indicadoras de contaminação fecal. No caso das chuvas, o escoamento superficial arrasta para dentro do lago grande parte dos detritos presentes na bacia de 


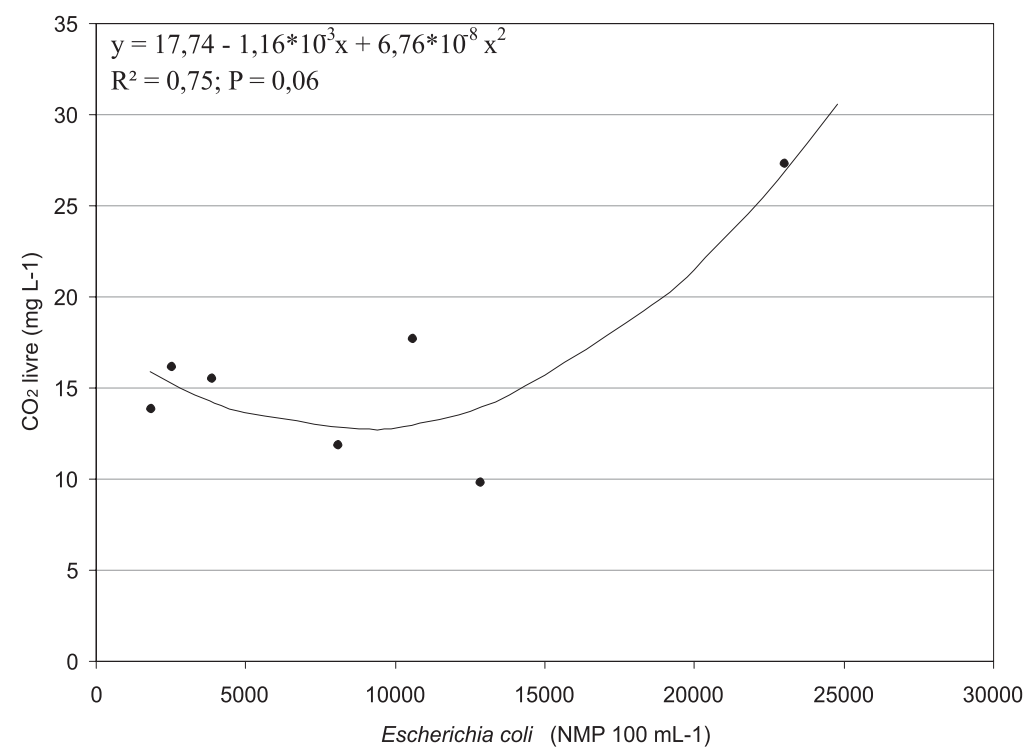

Figura 2 - Análise de regressão da concentração média de $\mathrm{CO}_{2}$ livre ( $\left.\mathrm{mg} \mathrm{L}^{-1}\right)$ na água da Lagoa da Parangaba (Fortaleza, Ceará), em função da concentração de Escherichia coli (NMP $100 \mathrm{~mL}^{-1}$ ). Os pontos em vermelho correspondem aos valores observados, que foram obtidos a partir de amostras de água sub-superficial coletas na entrada, meio e sangradouro da lagoa.

drenagem. Dentre esses, destacam-se fezes de animais, como cachorros, gatos e eqüinos. Ao se consultar as anotações realizadas em campo, verificou-se que na noite anterior ao dia 3 de maio de 2008, dia em que ocorreu o pico de concentração de E. coli na LP (22000 NMP $100 \mathrm{~mL}^{-1}$ ), ocorreu grande precipitação. Logo, os indícios mostram que o pico de E. colina LP verificado no presente trabalho se deveu a ação das chuvas ocorrido no período, que lavou a superfície do solo, levando para dentro do ecossistema grande quantidade de sujeira.

Barreto et al. (2006) observaram que as concentrações de E. coli na LP variaram de $1,1 \times 10^{3}$ a $1,1 \mathrm{x}$ $10^{6} \mathrm{NMP} 100 \mathrm{~mL}^{-1}$, em estudo realizado no período de junho a setembro de 2002. Esses autores concluíram que a falta de saneamento básico próximo a LP contribui para a poluição de suas águas, pondo em risco as famílias que dela dependem para abastecimento e pesca

A concentração média de $\mathrm{CO}_{2}$ livre na água subsuperficial da LP $\left(16,0 \mathrm{mg} \mathrm{L}^{-1}\right)$ está acima do limite máximo aceitável para bom desenvolvimento dos peixes, que é de $10 \mathrm{mg} \mathrm{L}^{-1}$. Nesse caso, o excesso de $\mathrm{CO}_{2}$ livre na água dificulta as trocas respiratórias, estressando os animais. Como conseqüências, eles aproveitam pior o alimento ingerido, crescem menos e se tornam mais suscetíveis a doenças oportunistas (Boyd, 1992).

A Figura 2 apresenta o ajuste gráfico realizado aos resultados observados do relacionamento entre a concentração média de $\mathrm{CO}_{2}$ livre na água, em $\mathrm{mg} \mathrm{L}^{-1}$, em função da concentração média de $E$. coli, em NMP $100 \mathrm{~mL}^{-1}$. A análise de regressão produziu a equação polinomial de $2^{\underline{a}}$ ordem $y=17,74-1,16^{*} 10^{-3} x+6,76^{*} 10$
${ }^{8} \mathrm{X}^{2}$, onde y é a concentração média de $\mathrm{CO}_{2}$ livre na água sub-superficial da $L P$, em $\mathrm{mg} \mathrm{L}^{-1}$, e x é a concentração média de E. coli, em NMP $100 \mathrm{~mL}^{-1}$. Tal regressão apresentou coeficiente de determinação $R^{2}$ igual a 0,75 , o que significa que $75 \%$ das variações da concentração média de $\mathrm{CO}_{2}$ livre na água sub-superficial da LP, em função da concentração média de E. coli, podem ser explicadas pela equação acima. Contudo, ao se proceder a análise de variância da regressão polinomial em questão, obteve-se valor de probabilidade $(P=0,06)$ acima do valor mínimo para considerar o ajuste como significativo, do ponto de vista estatístico $(P=0,05)$.

O relacionamento positivo entre a concentração de E. coli, em NMP $100 \mathrm{~mL}^{-1}$, e a concentração de $\mathrm{CO}_{2}$ livre na água, em $\mathrm{mg} \mathrm{L}^{-1}$, pode ser explicado pela liberação desse gás na água pela atividade decompositora da matéria orgânica. As elevações nas concentrações de E. coli na água se devem, geralmente, ao aporte de esgotos domésticos e/ou de poluição urbana difusa, proveniente da lavagem da superfície do solo pelas chuvas. Tanto os esgotos como a poluição difusa são ricos em matéria orgânica, seja particulada ou dissolvida. A ação das bactérias decompositoras sobre a matéria orgânica tem efeitos diretos sobre as concentrações de oxigênio dissolvido e gás carbônico na água, reduzindo o primeiro e elevando o último. As elevadas concentrações de $\mathrm{CO}_{2}$ livre na água, além de estressarem os animais presentes no ecossistema, acidificam o meio. Isso se deve à reação ácida do $\mathrm{CO}_{2} \mathrm{com}$ a água, formando ácido carbônico, como citado anteriormente.

Portanto, os afluentes da LP ricos em matéria orgânica, grande parte da qual de origem fecal, aumentam não somente o risco de doenças à população que 
se utiliza desse manancial, como também afetam o desenvolvimento das populações animais que vivem na mesma. Em resumo, a água se torna contaminada ( $E$. coll), hipóxica e ácida.

A análise de regressão realizada para o relacionamento da concentração de E. coli, em NMP $100 \mathrm{~mL}^{-}$ ${ }^{1}$, como variável independente, e a concentração de $\mathrm{CO}_{2}$ livre na água sub-superficial, em mg L-1, como variável dependente, apesar de não significativa, apresentou valor de probabilidade $\mathrm{P}$ bem próximo a 5\% (6\%). Nesse caso, há indícios que sugerem que há de fato relacionamento positivo entre as concentrações de E. colie $\mathrm{CO}_{2}$ livre, de acordo com o ajuste polinomial apresentado no presente trabalho.

\section{CONCLUSÕES}

Os resultados obtidos no presente trabalho permitem concluir que:

1. Houve relação direta entre as concentrações de Escherichia colie $\mathrm{CO}_{2}$ livre da água sub-superficial da Lagoa da Parangaba, com tendência de expressão pela equação $y=17,74-1,16^{*} 10^{-3} x+6,76^{*} 10$ ${ }^{8} \mathrm{X}^{2}$, onde y é a concentração média de $\mathrm{CO}_{2}$ livre, em $\mathrm{mg} \mathrm{L}^{-1}$, e $\mathrm{x}$ é a concentração média de $E^{2}$. coli, em NMP $100 \mathrm{~mL}^{-1}\left(R^{2}=0,75 ; P=0,06\right)$;

2. Os afluentes da Lagoa da Parangaba ricos em matéria orgânica, grande parte da qual de origem fecal, aumentam não somente o risco de doenças à população que se utiliza desse manancial, como também afetam o bom desenvolvimento das populações animais que vivem na mesma;

3. As águas da Lagoa da Parangaba estão altamente contaminadas por E. coli , são ácidas e sofrem eventuais episódios de hipóxia.

\section{REFERÊNCIAS}

American Public Health Association - APHA. 1999. Standard methods for the examination of water and waste water. 20를 Edição. APHA, Washington, 630 p.

Arana, L.V. 2000. Princípios químicos da qualidade da água em aqüicultura: uma revisão para peixes e camarões. 2ª Edição. EDUFSC, Florianópolis, 231 p.

Barreto, N.S.E.; Vieira, R.H.S.F; Lima, E.A.; Sousa, D.B.R.; Nunes, V.V.F. \& Rodrigues, D.P. 2006. Avaliação microbiológica de águas de lagoa e açude em Fortaleza, CE e sua relevância em saúde pública. Higiene Alimentar. 20(139): 99-103.
Boyd, C.E. 1992. Water quality management for pond fish culture. Developments in Aquaculture and Fisheries Science, 9. 1a Edição. Elsevier, Amsterdam, $318 \mathrm{p}$.

Boyd, C.E. \& Tucker, C.S. 1998. Pond Aquaculture Water Quality Management. 1a Edição. Kluwer, Norwell, $720 \mathrm{p}$.

Conselho Nacional Do Meio Ambiente - CONAMA. 2005. Resolução no 357 de 17 de março de 2005. Ministério do Meio Ambiente. 23 p.

Danley, M.L.; Kenney, P.B.; Mazik, P.M.; Kiser, R. \& Hankins, J.A. 2005. Effects of carbon dioxide exposure on intensive cultured rainbow trout Oncorhynchus mykiss physiological responses and fillet attributes. J. of the World Aquac. Soc. 36(3): 249-261.

Dodds, W.K.. 2002. Freshwater ecology: concepts \& environmental applications (Aquatic ecology). 1 $1^{\text {a }}$ Edição. Academic Press, New York, 592 p.

Esteves, F.A.. 1998. Fundamentos de Limnologia. $2^{\mathrm{a}}$ Edição. Interciência, Rio de Janeiro, 601 p.

Fantin-Cruz, I.; Loverde-Oliveira, S. \& Girard, P. 2008. Caracterização morfométrica e suas implicações na limnologia de lagoas do Pantanal Norte. Acta Sci. Biol. Sci., 30(2): 133-140.

Golombieski, J.I.; Marchezan, E.; Monti, M.B.; Storck, L.; Camargo, E.R. \& Santos, F.M. 2005. Qualidade da água no consórcio de peixes com arroz irrigado. Ciência Rural. 35(6): 1263-1268.

Higgins, J. \& Hohn, C. 2008. Effects of prevalent freshwater chemical contaminants on in vitro growth of Escherichia coli and Klebsiella pneumoniae. Environmental pollution. 152(2): 259-266.

Kulkoyluoglu, O.; Dugel, M. \& Kilic, M. 2007. Ecological requirements of Ostracoda (Crustacea) in a heavily polluted shallow lake, Lake Yenicaga (Bolu, Turkey). Hydrobiologia. 585(1): 119-133.

Sá, M.V.C., 2003. Absorção aparente, biodisponibilidade relativa e suplementação ótima de zinco em dietas para tilápia do Nilo (Oreochromis niloticus). Tese de Doutorado. UNESP: Botucatu, $189 \mathrm{p}$.

Wetzel, R.G.. 2001. Limnology - Lake and river ecosystems. 3 ${ }^{a}$ Edição. Academic Press, San Diego, $1006 \mathrm{p}$.

Yanbo, W.; Wenju, Z.; Weifen, L. et al., 2006. Acute toxicity of nitrite on tilapia (Oreochromis niloticus) at different external chloride concentrations. Fish Physiology and Biochemistry. 32:49-54. 